\title{
PARTICULATE MATTER CHARACTERIZATION IN AN INDOOR WORKPLACE ENVIRONMENT OF A LANDFILL
}

\section{CHALVATZAKI E. LAZARIDIS M. ${ }^{*}$}

Received: 08/03/2015

Accepted: 05/05/2015

Available online: 07/05/2015
Department of Environmental Engineering

Technical University of Crete, Chania, Greece

\begin{abstract}
The current study focus on the quantification of the particulate matter $\left(\mathrm{PM}_{10}\right)$ concentrations at the workplace environment of a manual waste sorting of a landfill using portable real-time photometric monitors. Increased $\mathrm{PM}_{10}$ mass concentrations were measured during the process of manual sorting of waste. It is observed that the daily average $\mathrm{PM}_{10}$ concentration on working days was equal to $149 \mu \mathrm{g} \mathrm{m}^{-3}$ while the corresponding daily $\mathrm{PM}_{10}$ concentration on non-working days was equal to $42 \mu \mathrm{g} \mathrm{m}^{-3}$. Furthermore, the average concentration of $\mathrm{PM}_{10}$ was equal to $209 \mu \mathrm{g} \mathrm{m}^{-3}$ during working hours while during non working hours was equal to $48 \mu \mathrm{g} \mathrm{m}^{-3}$. An indoor mass balance model was applied to estimate the $\mathrm{PM}_{10}$ mass emission rates, as well as the particle loss rates due to all removal processes. A good agreement was obtained between the model predictions and the measurements. In addition, the $\mathrm{PM}_{10}$ field measurements were further analysed with the ExDoM (Exposure Dose Model) human dosimetry model which used for calculating the human exposure and the deposition dose, clearance, and finally retention of particles in the human respiratory tract (RT).
\end{abstract}

Keywords: Emission rates, Landfill workers, Exposure, Dose, Mass balance model, ExDoM.

\section{Introduction}

Indoor air pollution in workplace and residential environments caught attention of scientists and the public in recent years (Lee and Chang, 2000; WHO 2010). Indoor exposure to air pollutants causes very significant damage to health and has been identified as one of the most critical global environmental problems especially in developing countries (WHO, 2010). Typically higher indoor concentrations occur in developing rather than developed countries. Indoor air pollutants have not been as extensively monitored as outdoor air pollutants and the evidence base for their contribution to health effects needs to be strengthened (Lazaridis and Colbeck, 2010; WHO, 2010). Many people are aware that outdoor air pollution can negatively impact human health, but most are unaware that indoor air pollution can be harmful as well (Taner et al., 2013). The indoor micro-environment has its own pollutants and pollution levels indoors may be higher than outdoor levels (Hoskins, 2003). The World Health Organization estimates that the global burden of disease from indoor air pollution is far greater than the burden from outdoor air pollution. Indoor air pollution is reported to be responsible for $3 \%$ of the global burden of disease (WHO, 2010). Therefore, quantification of emissions from indoor sources is very important for assessment of human exposure to harmful aerosol particles (Hussein et al., 2006).

Particulate Matter (PM) is considered to be an important factor that contributes to the perceived quality of the indoor environment and is one of the most important indoor air pollutants that could cause a number of adverse health effects (Morawska and Salthammer, 2003). Especially, in industrial sites, the 
exposure to PM presents a potential health threat for workers (Glytsos et al., 2013). However, few studies have presented quantitative determinations of aerosol particle emissions during indoor activities. There is usually more information available on emission characteristics, such as emission factors or emission rates, of outdoor particle sources than of indoor sources (He et al., 2004). The evaluation of indoor air pollution problems requires an understanding of several factors, including (Morawska and Salthammer, 2003): the source of the indoor pollutants, air exchange between the building and the outdoors, air movement within the building, resuspension of particles deposited on surfaces and removal of particles from the indoor environment by ventilation.

Exposure to PM can occur via respiratory, dermal and ingestion pathways and has been associated with increased human morbidity and mortality by many epidemiological studies (Dockery et al., 1993; Pope, 1995; Pope et al., 2002). The major pathway for PM to enter the human body is via the respiratory system (Salma et al., 2002). Health effects of PM are determined by their size distribution, chemical and microbiological concentration and composition (Griffin et al., 2001; Hetland et al., 2004). Particles larger than $10 \mu \mathrm{m}$ are efficiently removed in the nasal cavity and are therefore not of great potential danger. Particles less than 10 micrometres in diameter $\left(\mathrm{PM}_{10}\right)$ pose a health concern because they can be inhaled, and accumulate in the respiratory system. Furthermore, different sizes of airborne particles affect different regions of the respiratory system including 0.4-0.7 $\mu \mathrm{m}$ (alveolar), 0.7-1.1 $\mu \mathrm{m}$ (alveo-bronchial), 1.1-2.1 $\mu \mathrm{m}$ (bronchial), 4.7-5.8 $\mu \mathrm{m}$ (trachea-bronchial) and 5.8-10 $\mu \mathrm{m}$ (extrathoraric) (Ny and Lee 2011). Therefore, particle size distribution is important because it plays a major role in determining the dose and the region affected in the human respiratory tract role in determining both the inhaled dose and the region affected by particle hazards (Johnson and Esmen, 2004; Koehler and Volckens, 2013).

In the current work, the focus is on the quantification of the $\mathrm{PM}_{10}$ concentrations at a site of manual waste sorting in a landfill. Additionally, a mass balance model was adapted in order to estimate the emission rates of particles sources within the investigated indoor environment. Furthermore, the Exposure Dose Model (ExDoM; Aleksandropoulou and Lazaridis, 2013) is used for the estimation of the deposited dose and retention of aerosol particles in the respiratory tract (RT) of adult workers at the site of manual waste sorting.

\section{Materials and Methods}

\subsection{Description of the site}

The site of manual waste sorting is located at the Akrotiri landfill at the northeast part of the prefecture of Chania on the island of Crete (Greece). The Akrotiri landfill is located in the north-eastern part of the prefecture of Chania, $17 \mathrm{~km}$ to the east of the city of Chania and $4 \mathrm{~km}$ of the airport. The manual sorting of waste was taking place for about $15 \mathrm{~h}$ each day, divided in two shifts. The first shift started at 06:30 and ended at 14:30 while the second shift started at 14:30 and ended at 21:30. Each shift consists of 14 staff. In the first shift operating two waste lines: (1) recyclable line (blue bin) (2) mixed waste line which presents organic material together with the recyclable (green bin) while in the second shift operating only one waste line (recyclable line; blue bin). Cleaning of the area was performed for about half hour at the end of the second shift while the manual sorting of waste was not operating on Sundays.

\subsection{Microenvironmental Mass balance model}

A mass balance method was used to determine the $\mathrm{PM}_{10}$ emission rates from the workplace of manual sorting of waste of a landfill. In particular, a mass balance differential equation for a certain period of time (t) can be described by the equation (Glytsos et al., 2013):

$$
\frac{d C_{m}}{d t}=\lambda P C_{m, o u t}-\left(\lambda+\lambda_{\text {loss }}\right) C_{m}+\frac{E_{m}}{V}
$$


where $C_{m}$ and $C_{m \text {,out }}$ are the indoor and outdoor particle mass concentrations $\left(\mu \mathrm{g} \mathrm{m}^{-3}\right), V$ is the volume of the indoor environment $\left(\mathrm{m}^{3}\right), \mathrm{P}$ is the penetration factor, $\lambda$ is the ventilation rate $\left(\mathrm{min}^{-1}\right), \lambda_{\text {loss }}$ is the particle loss rate due to all removal processes and $E_{m}$ is the emission rate of indoor sources $\left(\mu \mathrm{g} \mathrm{min}^{-1}\right)$.Since the indoor $\mathrm{PM}_{10}$ levels during the manual waste sorting are much higher than the outdoor concentrations due to high indoor emission rates, the outdoor mass concentration was ignored for the calculations. Therefore the term corresponding to outdoor source in the equation (1) can be neglected and the equation can be written as:

$$
\frac{d C_{m}}{d t}=-\left(\lambda+\lambda_{\text {loss }}\right) C_{m}+\frac{E}{V}=-\lambda_{\text {tot }} C_{m}+\frac{E}{V}
$$

where, $\lambda_{\text {tot }}$ is the total particle loss rate due to the deposition and transport to the outdoor air.

The term $\lambda_{\text {tot }}$ of indoor aerosol particle mass concentrations was estimated using the equation (2) during the period of no activity indoors. It can be assumed that there were no significant indoor sources of particles for the time period just after the end of the second shift, when the personnel left the facility. Therefore, the term corresponding to indoor sources can be neglected $(E / V=0)$ and the equation can be written as:

$$
\frac{d C_{m}}{d t}=-\lambda_{\text {tot }} C_{m}
$$

A detailed description of the indoor mass balance model is given by Glytsos et al., (2013).

\subsection{Exposure and dose assessment model (ExDoM)}

The Exposure and Dose Model (ExDoM; Aleksandropoulou and Lazaridis, 2013) can simulate the dynamics of respirable particulate matter in human airways. The model estimates the individual's dose as a function of the exposure concentration, the ventilation rate and the deposition fraction of particles in the respiratory tract. The individual's dose - rate $\mathrm{H}\left(\mu \mathrm{g} / \mathrm{m}^{3}\right)$ is calculated as:

$$
H=\sum B C_{i} n_{i, j}
$$

where $C_{i}$ is the exposure concentration $\left(\mu \mathrm{g} \mathrm{m}^{-3}\right)$ for particles in the size fraction $i, B$ the ventilation rate of the exposed individual $\left(\mathrm{m}^{3} \mathrm{~h}^{-1}\right)$, and $\mathrm{n}_{\mathrm{i}, \mathrm{j}}$ the deposition fraction in region $\mathrm{j}$ of the respiratory tract for particles in the size fraction i. A detailed description of the model can be found in Aleksandropoulou and Lazaridis (2013). In the current study the ExDoM was applied to determine the dose for a Caucasian male for three exposure scenarios: (a) for a worker on the first shift, (b) for a worker on the second shift and (c) for a non-worker. The objective of using different exposure scenarios is to determine whether the particulate matter dose of workers at the site of manual waste sorting is elevated compared to that of the general population in the area. The activity pattern employed in the current study included exposure to particles in both the indoor and the outdoor environment, as presented in Table 1.

Table 1. Exposure scenarios for a Caucasian male for the two working shifts and a non-worker at the site of manual waste sorting

\begin{tabular}{c|c|c|c}
\hline Activity & Worker on the first shift & $\begin{array}{c}\text { Worker on the second } \\
\text { shift }\end{array}$ & $\begin{array}{c}\text { Non-worker at the site } \\
\text { of manual waste sorting. }\end{array}$ \\
\hline Sleep (home) & $22: 30-06: 30$ & $00: 30-08: 30$ & $22: 30-06: 30$ \\
\hline Light exercise (work) & $06: 30-14: 30$ & $14: 30-21: 30$ & $06: 30-14: 30$ \\
\hline Sitting (home) & $14: 30-17: 30$ & $21: 30-00: 30$ & $14: 30-17: 30$ \\
\hline Light exercise (home) & $17: 30-19: 30$ & $08: 30-11: 30$ & $17: 30-19: 30$ \\
\hline Sitting (background area) & $19: 30-22: 30$ & $11: 30-14: 30$ & $19: 30-22: 30$ \\
\hline
\end{tabular}


In the third scenario (non-worker), calculations are performed for an adult Caucasian male exposed to $\mathrm{PM}_{10}$ concentrations outdoors at a background area during working hours, approximately $10 \mathrm{~km}$ away from the Akrotiri landfill. During the rest of the day exposure to $\mathrm{PM}_{10}$ occurs indoors and outdoors in the vicinity of the background station. The background outdoor $\mathrm{PM}_{10}$ concentration was used to estimate the indoor (home) $\mathrm{PM}_{10}$ concentration characteristics, using the indoor/outdoor $\mathrm{PM}_{10}$ concentration ratio (approximately 0.7) for exposure. This ratio was obtained from Chalvatzaki et al. (2012) by the analysis of measurements, performed at an apartment (in the absence of indoor sources) located in the residential area in the vicinity of the background station. This result is in agreement with the study by Morawska and Salthammer (2003). Morawska and Salthammer (2003), concluded that, for naturally ventilated buildings in the absence of indoor sources, indoor/outdoor $\mathrm{PM}_{10}$ concentration ratio ranged from 0.5 to 0.98 with a median value of 0.7 .

\subsection{Measurements of particulate matter and mass size distributions}

The $\mathrm{PM}_{10}$ measurements at the site of manual waste sorting were performed using the TSI's DustTrack DRX aerosol monitor (Model 8534) which is a portable, battery-operated, laser-photometer that measures airborne dust concentrations. The instrument employs a light-scattering laser photometer for measuring aerosol mass concentrations (TSI, 2003). The measurements of $\mathrm{PM}_{10}$ using the DustTrack DRX aerosol monitor were performed for the period 11-17 October 2010. The Dusttrak ${ }^{\mathrm{TM}}$ instrument measurements were corrected based on a formula derived from comparative measurements with a beta attenuation monitor (FH 62 SEQ). The correction formula can be expressed as: beta [Attenuation Monitor Concentration] $\left(\mu \mathrm{g} \mathrm{m}^{-3}\right)=0.80$ [Dusttrak Monitor Concentration] $\left(\mu \mathrm{g} \mathrm{m}^{-3}\right)+10.4$ (Chalvatzaki et al., 2012). Furthermore, $\mathrm{PM}_{10}$ measurements at the background station were performed using the FH 62 SEQ particulate monitor (Thermo, 2003). The station is located at a background site approximately $10 \mathrm{~km}$ away from the Akrotiri landfill.

The size distribution of $\mathrm{PM}_{10}$ is required for the implementation of the ExDoM model and therefore impactor measurements were performed both at the background area (Chalvatzaki et al., 2012) and at the site of manual waste sorting using an Andersen cascade impactor. The Andersen sampler is a cascade impactor which consists of eight aluminium plates and one backup stage (non-viable, eight stage, Series 20-800, Thermo Scientific). The filters used for particle collection were dried before and after sampling in a laboratory room with constant temperature and relative humidity for a $24 \mathrm{~h}$ period. In order to determine the aerosol mass concentration, the filters were weighted before and after sampling using a Sartorius balance (Sartorius CP 225D, Sartorius AG, Goettingen, Germany).

\section{Results and discussion}

\subsection{Indoor particle mass concentration at the site of manual waste sorting}

Elevated $\mathrm{PM}_{10}$ mass concentrations were measured at the site of manual waste sorting. The daily time trend of $\mathrm{PM}_{10}$ particle concentration is shown in Figure 1 (60 min average mass concentration) during the working days.

The daily periodicity is clearly depicted with the concentration increasing at the beginning of the working shift and decreasing after the end of the second shift. The analysis of the data showed that elevated $\mathrm{PM}_{10}$ concentration values were observed until 21:30, when the second shift ended. The measurements showed that during the working hours, there was an increase of the $\mathrm{PM}_{10}$ concentration compared to the non working hours. It is observed that the average concentration of $\mathrm{PM}_{10}$ was equal to $209 \mu \mathrm{g} \mathrm{m}^{-3}$ during working hours (06:30-21:30) while during non-working hours (21:30-06:30) was equal to $48 \mu \mathrm{g} \mathrm{m}^{-3}$. The collected data showed that the mass concentration started to decline after the end of the working period, but remained throughout the night above $35 \mu \mathrm{g} \mathrm{m}^{-3}$. Furthermore, the $\mathrm{PM}_{10}$ concentrations decreased substantially after the break of $30 \mathrm{~min}$ for each shift. The break $(30 \mathrm{~min})$ of the first shift started approximately at 09:45 while the break (30 $\mathrm{min}$ ) of the second shift started approximately at 17:30. In order to protect the health of people working in industrial places, the Occupational Safety \& Health 
Administration (OSHA) of the US Department of Label has established an 8- $\mathrm{hr}$ permissible exposure limits of $15,000 \mu \mathrm{g} \mathrm{m}^{-3}$, measured as total particulate and the $5,000 \mu \mathrm{g} \mathrm{m}^{-3}$ limit for respirable particulates $\left(\mathrm{PM}_{10}\right)$. The indoor concentration at the site of manual waste sorting did not exceed the above limits, since the maximum 8-hr average $\mathrm{PM}_{10}$ concentration recorded was below $300 \mu \mathrm{g} \mathrm{m}^{-3}$. In particular, the $8 \mathrm{~h}$ average concentration for the first shift ranged between 155 and $279 \mu \mathrm{g} \mathrm{m}^{-3}$ while for the second shift ranged between 96 and $283 \mu \mathrm{g} \mathrm{m} \mathrm{m}^{-3}$. However, $\mathrm{PM}_{10}$ concentrations were exceeding the $\mathrm{EU}$ health protection standards (50 $\mu \mathrm{g} \mathrm{m}^{-3} ; 24-\mathrm{h}$ limit value). The daily $\mathrm{PM}_{10}$ concentrations at the site of manual waste sorting ranged from 95 to $187 \mu \mathrm{g} \mathrm{m}^{-3}$ during working days. Although the working personnel was equipped with filter masks, the elevated peak concentrations of $\mathrm{PM}_{10}$ particles and the probability presence of metals within these particles raise questions whether the current exposure limits are sufficient for the safety of the workers in the facility.

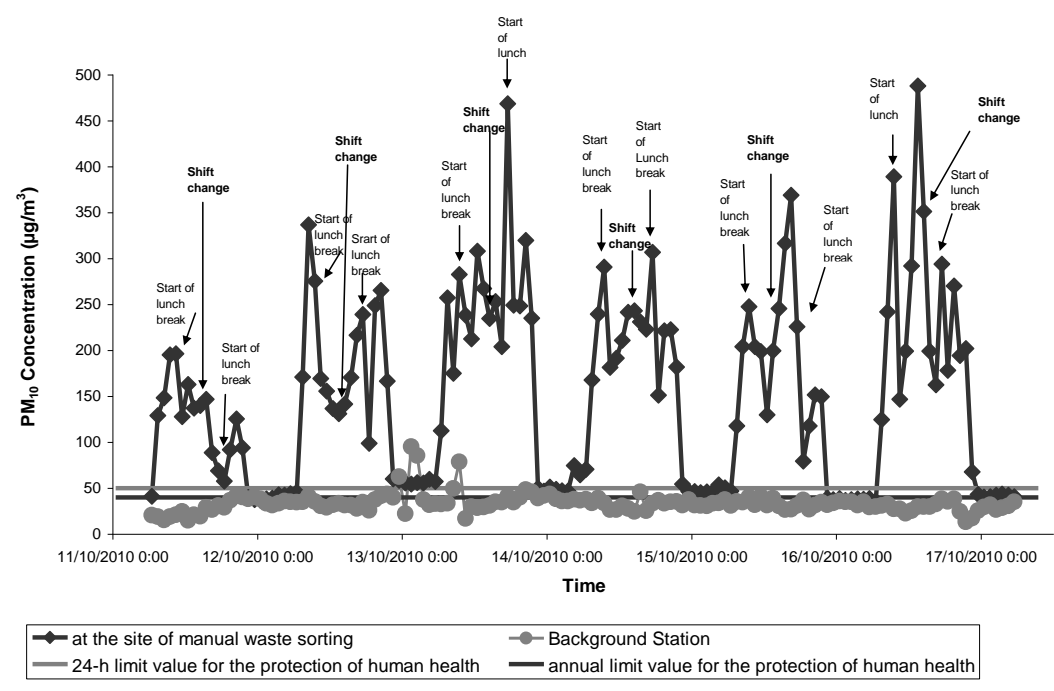

Figure 1. Sixty-minute average $\mathrm{PM}_{10}$ concentrations for the period 11-17 October 2010

\subsection{Calculation of particle emission rates from indoor sources at the site of manual waste sorting}

A microenvironmental mass balance model was applied to estimate the $\mathrm{PM}_{10}$ mass emission rates. The first step of the modelling procedure was to determine the total loss rate, $\lambda_{\text {tot }}$. The analysis of the $60-\mathrm{min}$ average data for the particles showed that at the end of the second shift the concentration started to decrease and finally reached almost constant values. Therefore, it can be assumed that there were no significant indoor sources of particles when the personal left the facility and the manual sorting of waste stopped (close to 21:30). The computed value for the coefficient $\lambda_{\text {tot }}$ using the above methodology was equal to $7.9 \times 10^{-3} \pm 4.0 \times 10^{-3} \mathrm{~min}^{-1}$ using the Equation (3). The next step was to calculate the emission rates of indoor sources. The analysis of the modelling results showed that the emission rates were not the same for the whole working day and that they were depended on the work load. Therefore, each working day was divided into distinctive time periods according to the estimated emission rates. Assuming that a working day starts at 06:30 and ends at the 21:30, segments of 6 time intervals with distinct emission rates were chosen. The estimated average emission rates are summarised in Table 2.

In this study, the measurements showed that the emissions of particles were higher at the beginning of the first shift (see Table 2). Higher emission rates were observed on the first shift due to the operation (approximately 4-hours) of the mixed waste line (presence of organic material together with the recyclable) at the beginning of the first shift. The final step of the modelling procedure was to apply the indoor model with the estimated values for the loss and the emission rates and compare the results with the experimental data. The comparison is depicted in Figure 2. 
Table 2. Estimated emission rates for $\mathrm{PM}_{10}$ concentrations for a working day starts at $06: 30$ and ends at the 21:30

\begin{tabular}{c|c|c|c|c|c|c}
\hline & \multicolumn{3}{|c|}{ First shift } & \multicolumn{3}{c}{ Second shift } \\
\hline Time period & $\begin{array}{c}06: 30- \\
09: 30\end{array}$ & $\begin{array}{c}09: 30- \\
11: 30\end{array}$ & $\begin{array}{c}11: 30- \\
14: 30\end{array}$ & $\begin{array}{c}14: 30- \\
17: 30\end{array}$ & $\begin{array}{c}17: 30- \\
18: 30\end{array}$ & $\begin{array}{c}18: 30- \\
21: 30\end{array}$ \\
\hline $\begin{array}{c}\text { Emission rates } \\
\left(\mu \mathrm{g} \mathrm{m}^{-3} \mathbf{~ m i n}^{-1}\right)\end{array}$ & $2.75 \pm 1.06$ & $1.30 \pm 1.50$ & $2.14 \pm 1.91$ & $1.97 \pm 1.99$ & $0.71 \pm 1.14$ & $1.67 \pm 1.25$ \\
\hline
\end{tabular}

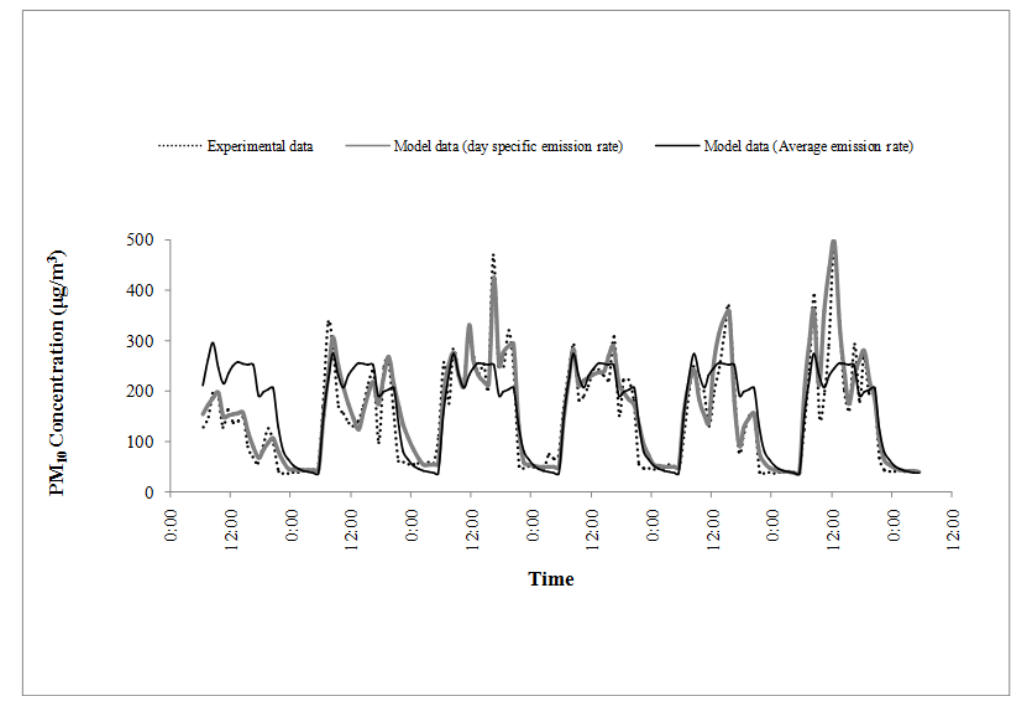

Figure 2. Comparison of the average 60 min measured $\mathrm{PM}_{10}$ concentration values with the model results for the period 11-17 October 2010

The model calculations were carried out with the different emission rates computed for each day and also for the average values of the emission rates. The agreement of the model results, using different emission rates for each day was satisfactory $\left(r^{2}=0.9\right)$. In addition, the agreement of the model results, using average emission rates for all six days was satisfactory considering the variability of the source characteristics $\left(r^{2}=0.6\right)$. The above results indicate that microenvironmental mass balance models can be applied satisfactory in industrial indoor environments. On the other hand, the emissions during the manual sorting of waste were different for each working day and they were influenced by the total amount of waste sent to the facility which was not constant during the measurement period.

3.3 Calculation of the human exposure and respiratory tract dose of particulate matter using the ExDoM model

The particulate matter dose in the RT was calculated using the ExDoM model for adult Caucasian male workers at the site of manual waste sorting. Then, the mass of particles in each compartment of the RT and their fraction transferred to the GI tract, lymph nodes and blood is estimated by the ExDoM model taking into account the mechanical movement of particles between compartments and their absorption into blood.

Particularly, absorption in the blood is a two-stage process (ICRP, 1994): (1) the dissociation of the particles into material and (2) the uptake of material dissolved from particles or of material deposited in a soluble form. The dissolved or soluble material transferred from the blood to other organs of the human body. The movement of dissolved or soluble materials (e.g Pb, $\mathrm{Cr}, \mathrm{Mn}$ ) from the blood to other organs of the human body is not in the scope of this study.

The results of the ExDoM model are presented in the Figure 3. In particular, the cumulative exposure and dose are presented in the Figure 3 along with the cumulative dose delivered to the lower head airways and to the thoracic and pulmonary regions of the respiratory tract (depicted in Figures 3 as four regions 
of the RT). In addition, the accumulated mass on the respiratory tract surfaces of the exposed subject were calculated by the ExDoM model together with the dose received by the Gl tract through the mucociliary escalator and the amount of particles absorbed in blood.

For worker on first shift it is observed in Figure 3a that, of the $8.60 \times 10^{3} \mu \mathrm{g}$ of particles deposited to the RT (except for ET1), $7.23 \times 10^{3} \mu \mathrm{g}(84 \%)$ were transferred to the GI tract and $5.10 \times 10^{2} \mu \mathrm{g}(6 \%)$ were absorbed to blood (moderate absorption). Approximately $10 \%$ of the particles that were deposited to RT (except for ET1), remained there at the end of the exposure. For worker on the second shift it is calculated that $7.28 \times 10^{3} \mu \mathrm{g}$ of particles deposited to the RT (except for ET1). It was found that deposited dose to the RT (except for ET1) for an adult Caucasian male who is working on second shift is less by $15 \%$ compared for a worker on first shift due to the lower $\mathrm{PM}_{10}$ exposure. This is due to higher emission rates and consequently $\mathrm{PM}_{10}$ concentration on the first shift due to the operation of an additional line (mixed waste line which presents organic material together with the recyclable).

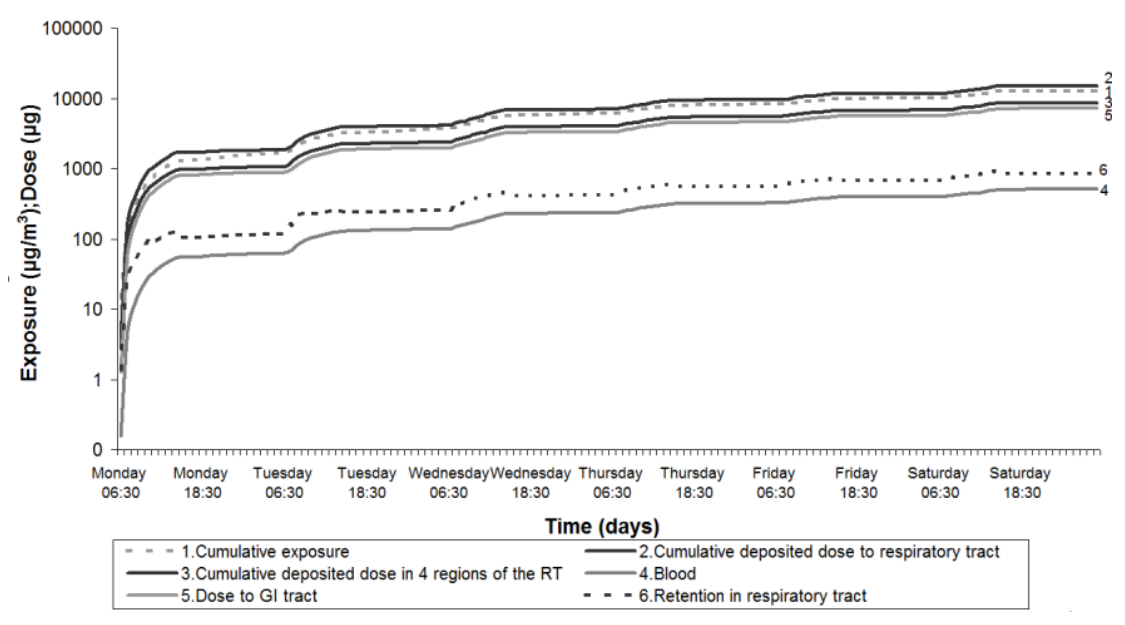

(a)

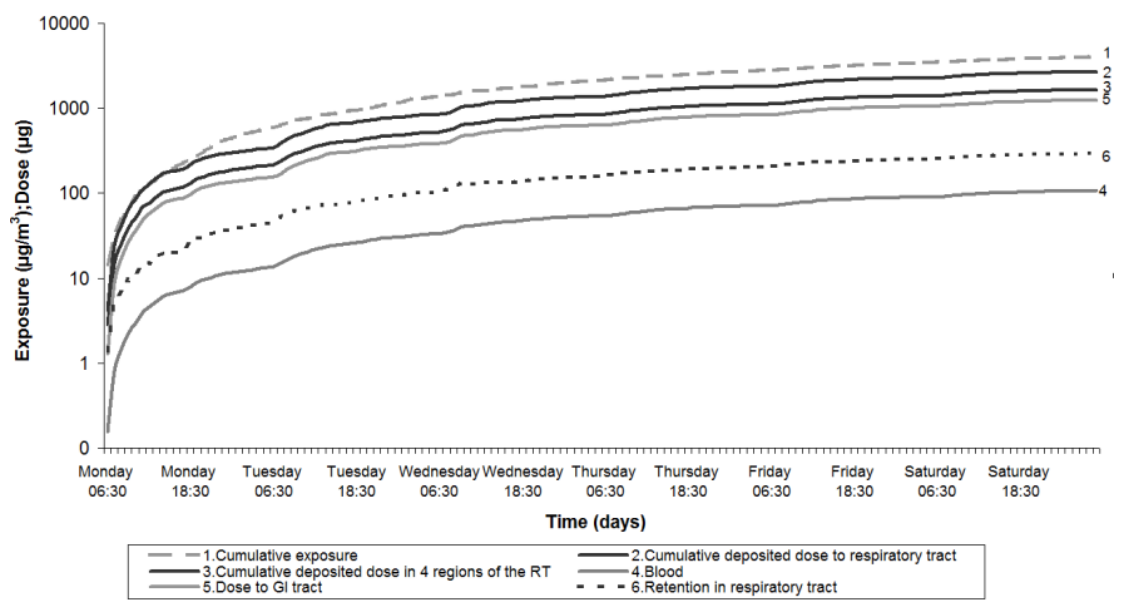

(b)

Figure 3: Cumulative exposure and dose of particles delivered to the lower head airways (ET2), the thoracic (BB and bb), and pulmonary (Al) regions of the respiratory tract (four regions of the RT) of an adult Caucasian (a) worker on first shift and (b) non-worker. The internal dose and retention of particles on the respiratory tract surfaces and the amount of material transferred to the GI tract and absorbed in blood are depicted (moderate clearance). 
Exposure and dose to $\mathrm{PM}_{10}$ for the adult Caucasian male who is not working at the landfill site are shown in Figure 3b. The individual has the same daily activity schedule with the worker on first shift however during the working hours he is exposed to lower $\mathrm{PM}_{10}$ concentrations outdoors at the background area. It is observed that, of the $1.64 \times 10^{3} \mu \mathrm{g}$ of particles deposited to the RT (except for ET1), $1.24 \times 10^{3} \mu \mathrm{g}$ (75 $\%)$ were transferred to the $\mathrm{Gl}$ tract and $1.07 \times 10^{2} \mu \mathrm{g}(7 \%)$ were absorbed to blood (moderate absorption). Approximately $18 \%$ of the particles that were deposited to RT, remained there at the end of the exposure. In addition, it is observed that $81 \%$ and $77 \%$ lower particle mass deposits to RT (except for ET1) compared with the worker on first and second shift, respectively due to the lower $\mathrm{PM}_{10}$ exposure. Furthermore, it is observed that $84 \%$ and $75 \%$ of the deposited particles in the respiratory tract were transferred to the GI tract of workers and non-workers, respectively. This discrepancy is due to the lower contribution of coarse particles to $\mathrm{PM}_{10}$ at the background area. In particular, as regards the size distribution at the background area, the percentage contributions of fine $\left(\mathrm{PM}_{2.1}\right)$ and coarse particles $\left(\mathrm{PM}_{10-2.1}\right)$ to $\mathrm{PM}_{10}$ were approximately $31 \%$ and $69 \%$ while at the site of manual waste sorting it were approximately $14 \%$ and $86 \%$, respectively.. Fine particles penetrate deeper in the lungs of the exposed subjects and have stronger acute respiratory effects compared to coarse particles whereas coarse particles are mainly deposited in the upper respiratory tract regions and transferred to the trachea by the mucociliary escalator and swallowed to the Gl tract which can cause gastrointestinal effect (Schwartz and Neas, 2000; Aleksandropoulou and Lazaridis, 2013; Milford et al. 2013). Therefore, more particles were transferred to the GI tract of workers due to elevated coarse fraction which can cause gastrointestinal effects. The elevated $\mathrm{PM}_{10}$ levels at the site of manual waste sorting resulted to increased human exposure. Therefore, the need to install a ventilation system coupled to dust filters which should also have to be cleaned regularly. Furthermore, the collected dust during the manual sorting work has to be transported in special sealed bags reducing therefore the human exposure.

\section{Conclusions}

Particulate measurements were performed at a site of manual waste sorting in a landfill. The indoor concentration at the site of manual waste sorting did not exceed the 8- $\mathrm{hr}$ permissible exposure limits as published by OSHA. In particular, the $8 \mathrm{~h}$ average concentration for the first shift ranged between 155 and $279 \mu \mathrm{g} \mathrm{m}^{-3}$ while for the second shift ranged between 96 and $283 \mu \mathrm{g} \mathrm{m}^{-3}$. However, $\mathrm{PM}_{10}$ concentrations were exceeding the EU health protection standards $\left(50 \mu \mathrm{g} \mathrm{m}^{-3}\right)$. Furthermore, a mass balance model was applied in conjunction with the experimental data to estimate the aerosol mass emission rates. In particular, during working hours, $\mathrm{PM}_{10}$ mass emission rates ranged between 0.71 and $2.75 \mu \mathrm{g} \mathrm{m}^{-3} \mathrm{~min}^{-1}$. The comparison between the model predictions and the measurements was satisfactory, indicating that microenvironmental mass balance models can be applied in industrial indoor environments. In addition, the $\mathrm{PM}_{10}$ concentrations were analysed with the ExDoM model which calculates the deposition, dose and finally retention of aerosol particles in the respiratory tract. It was observed that $84 \%$ of particles deposited in the RT (except for ET1) of an adult Caucasian worker were transferred to the Gl tract while 6 $\%$ were absorbed to blood and $10 \%$ were retained in the four lower regions of the respiratory tract. The elevated $\mathrm{PM}_{10}$ levels at the site of manual waste sorting resulted to increased human exposure and therefore additional measures have to apply to reduce the concentration of particulate matter.

\section{References}

Aleksandropoulou V. and Lazaridis M. (2013), Development and application of a model (ExDoM) for calculating the respiratory tract dose and retention of particles under variable exposure conditions, Air Qual Atmos Health, 6, 13-26.

Chalvatzaki E., Aleksandropoulou V., Glytsos T. and Lazaridis M. (2012), The effect of dust emissions from open storage piles to particle ambient concentration and human exposure, Waste Management, 32, 2456-2468.

Dockery D.W., Pope C.A., Xu X., Spengler J.D., Ware J.H., Fay M.E., Ferris B.G. and Speizer F.A. (1993), An association between air pollution and mortality in six U.S. cities, N. Engl. J. Med., 329, 1753-1759. 
Glytsos T., Ondracek J., Dzumbova L., Eleftheriadis K. and Lazaridis M. (2013), Fine and coarse particle mass concentrations and emission rates in the workplace of a detergent industry, Indoor Built Environ, doi.10.1177/1420326X13483765

Griffin D.W., Garrison V.H., Herman J.R. and Shinn E.A. (2001), African desert dust in the Caribbean atmosphere: microbiology and public health, Aerobiologia, 17, 203-213.

He C., Morawska L., Hitchins J. and Gilbert D. (2004), Contribution from indoor sources to particle number and mass concentrations in residential house, Atmospheric Environment, 38, 3405-3415.

Hetland R.B., Cassee F.R., Refsnes M., Schwarze P.E., Lag M., Boere A.J.F. and Dybing E. (2004), Release of inflammatory cytokines, cell toxicity and apoptosis in epithelial lung cells after exposure to ambient air particles of different size fractions, Toxicology in Vitro, 18, 203-212.

Hoskin J.A. (2003), Health effects due to indoor air pollution, Indoor Built Environ, 12, 427-433.

Hussein T., Glytsos T., Ondracek J., Dohanyosova P., Zdimal V., Hameri K., Lazaridis M., Smolik J. and Kulmala M. (2006), Particle size characterization and emission rates during indoor activities in a house, Atmospheric Environment, 40, 4285-4307.

Johnson D.L. and Esmen N.A. (2004), Method-induced misclassification for a respirable dust sampled using ISO/ ACGIH/CEN criteria, Ann Occup Hyg., 48, 13-20.

Koehler K.A. and Volckens J. (2013), Development of a Sampler to Estimate Regional Deposition of Aerosol in the Human Respiratory Tract, Ann. Occup. Hyg., 57, 1138-1147.

Lazaridis M. and Colbeck I. (2010), Human Exposure to Pollutants via Dermal Absorption and Inhalation, Environmental pollution, 17, $308 \mathrm{p}$.

Lee S.C. and Chang M. (2000), Indoor and outdoor air quality investigation at schools in Hong Kong, Chemosphere, 41, 109-113.

Milford C., Castell N., Marrero C., Rodriguez S., Sanchez de la Campa A.M., Fernadez-Camacho R., de la Rosa J. and Stein A.F. (2013), Measurements and simulation of speciated PM2.5 in south-west Europe, Atmospheric Environment, 77, 36-50.

Morawska L. and Salthammer T. (2003), Indoor environment: airborne particles and settled dust. Wiley-VCH, 450 pp.

Ny M.T. and Lee B.K. (2011), Size distribution of airborne particulate matter and associated metallic elements in an urban area of an industrial city in Korea, Aerosol Air Qual. Res., 11, 643-653.

Pope C.A., Bates D.V. and Raizenne M.E. (1995), Health effects of particulate air pollution: time for reassessment? Environ. Health Perspect., 103, 472-480.

Pope C.A., Burnett R.T., Thun M.J., Calle E.E., Krewski D., Ito K. and Thurston G.D. (2002), Lung cancer, cardiopulmonary mortality, and long-term exposure to fine particulate air pollution, JAMA-J. Am. Med. Assoc., 287, 1132-1141.

Salma I., Balashazy I., Winkler-Heil R., Hofmann W. and Zaray G. (2002), Effect of particle mass size distribution on the deposition of aerosols in the human respiratory system, Aerosol Science, 33, 119-132.

Schwartz J. and Neas L.M. (2000), Fine particles are more strongly associated than coarse particles with acute respiratory health effects in schoolchildren, Epidemiology, 11, 6-10.

Taner S., Pekey B. and Pekey H. (2013), Fine particulate matter in the indoor air of barbeque restaurants: Elemental compositions, sources and health risks, Science of the Total Environment, 454-455C, 79-87.

Thermo ESM Andersen Instruments GmbH (2003), Operating Manual, Particulate Monitoring Instrument, FH 62 I-R.

TSI (2003). Model 8534 DustTRAK DRX Aerosol Monitor. Operation and Service Manual.

WHO (2010). Guidelines for indoor air quality: selected pollutants. http://www.euro.who.int/_data/assets/pdf_file/0009/128169/e94535.pdf 